\title{
$\begin{array}{ll}\text { Research Square } & \text { Preprints are preliminary reports that have not undergone peer review. } \\ \text { They should not be considered conclusive, used to inform clinical practice, }\end{array}$ or referenced by the media as validated information. \\ Quantification of Optimal Target Reliability for Seismic Design: Methodology and Application to Midrise Steel Buildings
}

\section{Kasra Habibi}

Sharif University of Technology

\section{S. Saeid Hosseini Varzandeh}

Sharif University of Technology

Mojtaba Mahsuli ( $\square$ mahsuli@sharif.edu )

Sharif University of Technology https://orcid.org/0000-0001-7192-0881

\section{Research Article}

Keywords: Target reliability, Optimal design base shear, Detailed risk analysis, Lifecycle cost, Intermediate moment-resisting frame, Concentrically braced frame, Collapse

Posted Date: December 29th, 2021

DOI: https://doi.org/10.21203/rs.3.rs-1112108/v1

License: (c) (i) This work is licensed under a Creative Commons Attribution 4.0 International License. Read Full License 


\title{
Quantification of Optimal Target Reliability for Seismic Design: Methodology and Application to Midrise Steel Buildings
}

\author{
Kasra Habibi \\ M.Sc. Graduate, Center for Infrastructure Sustainability and Resilience Research, Dept. of Civil Engineering, Sharif University of \\ Technology, Tehran, Iran \\ S. Saeid Hosseini Varzandeh \\ Ph.D. Candidate, Center for Infrastructure Sustainability and Resilience Research, Dept. of Civil Engineering, Sharif University of \\ Technology, Tehran, Iran \\ Mojtaba Mahsuli \\ Associate Professor, Center for Infrastructure Sustainability and Resilience Research, Dept. of Civil Engineering, Sharif University \\ of Technology, Tehran, Iran; Corresponding Author: mahsuli@sharif.edu, Phone: +98 (21) 6616-4217, Fax: +98 (21) 6601-4828
}

\section{Abstract}

Quantification of the optimal target reliability based on the minimum lifecycle cost is the goal standard for calibration of seismic design provisions, which is yet to be fully-materialized even in the leading codes. Deviation from the optimally-calibrated design standards is significantly more pronounced in countries whose regulations are adopted from the few leading codes with no recalibration. A major challenge in the quantification of optimal target reliability for such countries is the lack of risk models that are suited for the local construction industry and design practices. This paper addresses this challenge by presenting an optimal target reliability quantification framework that tailors the available risk models for the countries from which the codes are adopted to the local conditions of the countries adopting the codes. The proposed framework is showcased through the national building code of Iran, which is adopted from the codes of the United States, using a case study of three midrise residential steel building archetypes. The archetypes have various structural systems including intermediate momentresisting frame (IMF) and special concentrically braced frame (SCBF). Each of these archetypes are designed to different levels of the base shear coefficient, each of which corresponds to a level of reliability. To compute the lifecycle cost, the initial construction cost of buildings is estimated. Next, robust nonlinear models of these structures are generated, using which the probability distribution of structural responses and the collapse fragility are assessed through incremental dynamic analyses. Thereafter, the buildings are subjected to a detailed seismic risk analysis. Subsequently, the lifecycle cost of the buildings is computed as the sum of the initial construction cost and the seismic losses. Finally, the optimal strength and the corresponding target reliability to be prescribed are quantified based on the notion of minimum lifecycle cost. The results reveal a 50-year optimal reliability index of 2.0 and 2.1 for IMF and SCBF buildings, respectively and an optimal collapse probability given the maximum considered earthquake of $16 \%$ for both systems. In the context on the case study of the national building code of Iran, the optimal design base shear for IMF buildings is $40 \%$ higher than the current prescribed value by the code, whereas that of SCBF buildings is currently at the optimal level.

Keywords: Target reliability; Optimal design base shear; Detailed risk analysis; Lifecycle cost; Intermediate moment-resisting frame; Concentrically braced frame; Collapse.

\section{Introduction}

Building codes prescribe the minimum standards to follow in order to achieve a preset target safety. This target has generally been determined through accepted practice. It means that the regulations have been calibrated against reliability levels of a set of representative structures, which had been designed to previous codes and has shown a satisfactory performance in past earthquakes. However, this approach 
has a number of unresolved issues. One of these issues is the subjective essence of what to accept as satisfactory, especially when it comes to human lives causing moral dilemmas (Douglas and Gkimprixis 2018). Another issue is its inefficiency in terms of assigning a limited budget to mitigate disaster-induced losses (Gudipati and Cha 2019) as it is unclear whether or not the present regulations are optimal (Rackwitz 2006).

The issues are exacerbated for many countries whose national building codes are either fully or partially adopted from other standards. Mahmoudkalayeh and Mahsuli (2021) categorize the building codes into three types in terms of originality. The first type prescribes fully original regulations, while the second and third types adopt all or parts of their regulations from the codes in the first category. However, such an adoption is not warranted in many cases as the target reliabilities set in the original source codes may not guarantee the intended satisfactory performance in the country whose codes are adopted. Moreover, many of the partially adopted codes do not even recalibrate their load and resistance factors based on the local construction industry, construction quality, or design practices. Hence, it is highly likely that such adopted codes fail to even meet the target reliability set by the source code (Mahmoudkalayeh and Mahsuli 2021).

This paper employs a holistic risk-based approach to quantify the optimal target reliability for seismic design. In this approach, the target reliability is quantified based on the notion of minimum lifecycle cost. The lifecycle cost is the sum of the initial construction cost and possible future losses due to such disasters as earthquakes. Although this approach is superior as it needs not subjective criteria, it may have a high computational cost since reliability levels should be evaluated for a considerable number of archetypical buildings (Gudipati and Cha 2019). Additionally, such an analysis requires a library of risk models, while these models are only available for a few countries. In countries the codes of which are adopted, the lack of the required risk models and the demanding task of developing them anew often impedes quantifying target reliabilities based on the local conditions. To remedy, the present paper introduces a novel approach to adapt the available risk models that have previously been developed for the country of the original code to the local conditions of the country which has adopted that code. This adaptation requires merely a few cost indicators as input. This, in turn, yields adjusted risk models that will be used for lifecycle cost analysis. As a result, the proposed approach simultaneously aims for two objectives: first, to facilitate the quantification of the target reliability based on the local conditions 
of the countries whose codes are adopted; second, to upgrade this quantification to a risk-optimal approach.

The state of the art on prescribing the seismic strength of buildings comprises three major approaches. The first approach is based on a uniform hazard, i.e., the peak ground acceleration (PGA) or the spectral acceleration $(\mathrm{Sa})$ at a prescribed return period. Examples of the codes employing such approach are Eurocode 8 (EN 1998-1 2004) and Standard No. 2800 of Iran (BHRC 2014). The seismic risk of buildings designed in accordance with this approach may vary significantly, and they may exhibit markedly different performance levels (Gkimprixis et al. 2020). In a quest for risk-targeted provisions, codes such as ASCE/SEI 7-16 (ASCE 2017) employed the second approach that is based on a target uniform risk. In this approach, the designed buildings would have a uniform probability of collapse over the course of their life or given a specified intensity, such as the maximum considered earthquake (MCE). Therefore, this approach also requires a target risk to be prescribed first, which is calibrated to the previous practice, i.e., to the uniform hazard approach, and is therefore not optimal. Another issue in this approach is the utilization of generic collapse fragility curves for all structural systems in order to avoid prescribing different design PGA for different structural systems (Douglas and Gkimprixis 2018). Such a generalization ignores the inherent differences in the reliability of various structural systems. This issue can be circumvented by reflecting this performance difference in the factors considered in seismic codes to account for nonlinearity, such as the response modification factor (Zaman and Ghayamghamian 2019). Another issue of this approach is that collapse is the sole consequence considered, and a wide range of damage is disregarded. Lastly, this approach does not account for the initial construction cost, which constitutes a major portion of the lifecycle cost of buildings (Gkimprixis et al. 2020). The third approach is the one employed in the present paper, which determines the optimal seismic strength based on the minimum lifecycle cost. In the following, the literature relevant to these three approaches is briefly reviewed.

Gkimprixis et al. (2020) compared the above-mentioned approaches based on uniform hazard, uniform risk, and minimum lifecycle cost to quantify the prescribed design PGA of the Eurocode 8. They concluded that although the design PGA insignificantly affects the initial construction cost, a change in the code is not warranted as it has minor benefits in terms of the reduction in the lifecycle cost. Zaman and Ghayamghamian (2019) emphasized the issues associated with the uniform hazard 
approach, and presented a risk-adjusted design PGA map for Tehran using the acceptance criteria of ASCE/SEI 7. Gudipati and Cha (2019) presented a framework for optimizing the target reliability of a portfolio of four buildings with steel special moment frames. They concluded that the optimal reliability index of different building categories may differ up to 19\%, and that the target reliability of ASCE/SEI 7 is not universally optimal. Ghasemi and Nowak (2017) proposed a procedure for quantifying the target reliability for steel girder bridges. They concluded that the more the structural importance and the severer the environmental conditions, the higher the target reliability.

To quantify the optimal target reliability in this paper, first a set of building archetypes are designed in accordance with seismic codes. The codes reflect the target safety level in the calibration of the prescribed earthquake load factor or equivalently, the design base shear coefficient. Therefore, in the present paper, each building archetype is designed to varying base shear coefficients, each of which corresponds to a level of reliability. Next, the initial construction cost of each building is assessed, and it is then subjected to a detailed risk analysis to evaluate its lifecycle cost and reliability index. It is expected that the reliability level has a direct relationship with the initial construction cost while having an inverse relationship with the probable seismic losses (Ghasemi and Nowak 2017). Eventually, the optimal prescribed strength level and the associated optimal target reliability are the ones with the minimum lifecycle cost.

In the next sections, first the methodology to assess the optimal reliability based on the local construction industry is presented. Then, the methodology is applied to evaluate the optimal reliability for a case study of three midrise steel building archetypes having various structural systems comprising intermediate moment-resisting frame (IMF), special concentrically braced frame (SCBF), and a combination of these systems. The archetypes are located in Tehran, Iran, whose national building codes are adopted from those of the United States (US) without quantifying the optimal target reliability based on the local construction industry and earthquake loading. Finally, the methodology is employed to quantify the optimal target reliability, and the required calibration to achieve that target is carried out.

127 This reveals the lacking safety in the current provisions which is a direct ramification of such a blind 128 adoption of the code. In addition, various insights on the performance of the examined building class are 129 provided. 


\section{Methodology}

131 This section first presents the general approach for quantification of the optimal target reliability. Next,

132 it lays out the steps to conduct the detailed risk analysis required in this quantification. Finally, it 133 introduces a method to transfer various seismic losses based on the local cost catalogs which enables the 134 quantification of the target reliability based on the local construction industry.

\section{$135 \quad 2.1$ Optimal Target Reliability}

136 The first step of the methodology is to design a set of building archetypes according to seismic codes.

137 The design procedure should be repeated to cover a range of reliability levels. Supposing that increasing

138 the earthquake design load would increase the gross lateral strength, lateral stiffness, and thus the 139 reliability of the building (Ang and De Leon 1997), the design base shear coefficient is chosen as the 140 decision variable here. Consequently, each building archetype is designed to at least six levels of the

141 design base shear coefficient starting with the one prescribed by the current regulations to at least twice

142 that value. The procedure is shown in the following equation:

$143 \quad c_{\mathrm{s}}=\alpha \cdot c_{\mathrm{s}, \text { code }}$

144 where $c_{\mathrm{s}}$ is the base shear coefficient to which the building is designed, and $\alpha$ is the coefficient used to

145

146

147

148

149

150

151

152

153

154

155

156

157

158 increase the design base shear coefficient prescribed by the code and represented by $c_{\mathrm{s}, \mathrm{code}}$.

Increasing the design base shear results in a subsequent increase in the dimensions of structural components in the lateral load resisting system. This, in turn, increases the initial construction cost of such components, whereas the construction cost of nonstructural components and of those structural components solely bearing gravitational loads are not affected. Therefore, the initial construction cost of a building designed to a different strength than that prescribed by the current code is computed only by adjusting the initial construction cost of structural components as follows:

$C_{o, j}=C_{o, 1}-C_{o s, 1}+C_{o s, j}$

where $C_{o, j}$ is the initial construction cost of the building designed to $\alpha_{j}, C_{o, 1}$ is the initial construction cost of the building designed to $\alpha_{1}$, i.e., according to the current code, which is hereafter referred to as the base building, $C_{o s, 1}$ is the construction cost of structural components at $\alpha_{1}$, and $C_{o s, j}$ is the construction cost of structural components at $\alpha_{j}$. The right-hand side of the equation is based on the cost catalogs of the target country evaluated for the base year. In the present paper, the year 2019 is chosen as the base year. 
Seismic losses should then be assessed, which requires detailed risk analysis of the buildings. For this purpose, the FEMA P-58 approach (FEMA 2018a) is employed, which has been implemented in the Performance Assessment Calculation Tool (PACT) software (FEMA 2018b). The FEMA P-58 approach employs the framing equation proposed by the Pacific Earthquake Engineering Research (PEER) center as the following triple integral:

$$
\lambda(D V>d v)=\int_{i m} \int_{d m} \int_{e d p} G(d v \mid d m) \cdot \mathrm{d} G(d m \mid e d p) \cdot \mathrm{d} G(e d p \mid i m) \cdot \mid \mathrm{d} \lambda(\text { im }) \mid
$$

165

166

167

168

169

170

171

172

173

174

175

176

177

178

179

180

181

182

183

184

185

186

where $\lambda$ represents the annual exceedance rate, $G($.$) is the complementary cumulative distribution$ function, $D V$ is the decision variable, $D M$ is the damage measure, $E D P$ is the engineering demand parameter, and $I M$ is the intensity measure (Cornell and Krawinkler 2000). As analytical solutions are not feasible, Monte Carlo sampling is employed to solve this triple integral (Yang et al. 2009). As such, this framework requires four analyses: hazard analysis, response analysis, damage analysis, and loss analysis. In the following subsection, the procedure implemented in this paper to conduct each one of these steps is discussed in more details.

After seismic losses are quantified, the lifecycle cost is computed as follows:

$$
\mathrm{E}\left[C_{\mathrm{LC}} \mid \mathbf{D}\right]=C_{o}(\mathbf{D})+\mathrm{E}\left[L_{\mathrm{t}, \mathrm{p}} \mid \mathbf{D}\right]
$$

where $\mathrm{E}\left[C_{\mathrm{LC}} \mid \mathbf{D}\right]$ is the expected annual lifecycle cost given the vector of design parameters $\mathbf{D}$, and $\mathrm{E}\left[L_{\mathrm{t}, \mathrm{p}} \mid \mathbf{D}\right]$ is the total expected annual loss given $\mathbf{D}$ discounted to the present value. After the lifecycle cost is computed, the optimum $\alpha$, represented by $\alpha^{*}$, is obtained by minimizing the lifecycle cost as follows:

$$
\alpha^{*}=\operatorname{argmin}\left\{\mathrm{E}\left[C_{\mathrm{LC}} \mid \mathbf{D}\right]\right\}
$$

The optimal reliability is the one that corresponds to $\alpha^{*}$. ASCE/SEI 7 expresses the target reliability under gravity loads in terms of a reliability index in 50 years or an annual probability of failure. In contrast, the target seismic reliabilities are implicitly built into a collapse probability of $1 \%$ in 50 years and 10\% given MCE. The former translates into a reliability index of 2.3 in 50 years using the following equation:

$\beta=\Phi^{-1}\left(1-P_{\mathrm{f}}\right)$

where $\beta$ is the reliability index, $\Phi^{-1}($.$) represents the standard normal inverse cumulative distribution$ function, and $P_{\mathrm{f}}$ is the probability of collapse in 50 years. 


\subsection{Detailed Risk Analysis}

188 The first step of the detailed risk analysis is hazard analysis. The main goal of this step is to produce hazard curves that present the exceedance probabilities of the intensity measure, e.g., PGA or $S a$. The second step is the response analysis of these buildings using an incremental dynamic analysis (IDA) (Vamvatsikos and Cornell 2002). For this analysis, detailed three-dimensional (3D) nonlinear finite element models of the building archetypes are generated and subjected to a suite of ground motion records at increasing levels of intensity. Such models for the archetypes in the application of this study will be presented later in this paper. The third step is the damage analysis using fragility curves that yield the probability of exceedance of various damage states. The final step is the loss analysis using consequence functions, which present the probability distribution of the loss given the damage state. The loss categories considered here comprise the direct economic loss due to repair or replacement, indirect economic loss due to downtime, social loss due to fatalities and injuries, and environmental impact due to carbon emission and embodied energy.

Finally, to evaluate the lifecycle cost, there is a need to express the non-monetary consequences in

201

202

203

204

205 terms of monetary losses. To this end, indirect economic losses are valued through rental and disruption rates to estimate losses associated with the quantified downtime, as follows:

$$
L_{\mathrm{ie}}=\left(T_{\mathrm{r}} \cdot r_{\mathrm{R}}+r_{\mathrm{O}} \cdot r_{\mathrm{D}}\right) \cdot A
$$

where $L_{\mathrm{ie}}$ is the indirect economic loss, $T_{\mathrm{r}}$ is the repair or replacement time of the building, $r_{\mathrm{R}}$ is the rental rate per unit area and time, $r_{O}$ is the owner occupancy rate, i.e., the ratio of the area occupied by owners to the total area of the building, $r_{\mathrm{D}}$ is the disruption rate per unit area, and $A$ is the total floor area. This equation charges the rental loss to the entire building but only charges the interruption losses due to relocation and shifting to owners (FEMA-NIBS 2012). To quantify environmental losses, first the embodied energy needed to repair or replace the building is turned into an equivalent amount of carbon emission. Then, the loss associated with the total emitted carbon is valued based on carbon taxes and fees. Also, the social losses are converted to monetary values using the notion of the value of a statistical life, hereafter denoted by $V_{\mathrm{SL}}$. It should be noted that this value is not the value of a human's life, but rather reflects the society's willingness-to-pay to improve life safety (Rackwitz 2006). In addition, the losses associated with injuries are taken as a fraction of the $V_{\mathrm{SL}}$ called the morbidity fraction. This fraction also accounts for the loss in the quality of life after the injury (Cropper and Sahin 2009). 
Recall that one of the objectives of this paper is to quantify the optimal target reliability for countries 217 whose codes are adopted from the pioneering original codes of other countries. The former countries are 218 hereafter referred to as "target" countries and the latter "source" countries. Coincidently, risk models are 219 often highly incomplete or entirely unavailable for the target countries. The primary challenge here is how to conduct the detailed risk analysis and the ensuing quantification of the optimal target reliability for a target country by adjusting the risk models that are currently available for the source country. In the following, each step of the detailed risk analysis is assessed from this point of view. The hazard analysis must be conducted locally for the location of the building considering the local sources of seismicity. The response and damage analyses can, in general, be carried out by utilizing the available finite element models and fragility curves whose parameters are quantified for the buildings designed to the original codes. This is owing to the fact that the building codes of the target country are adopted from those original source codes and consequently, the buildings designed to these codes must exhibit similar performances. As such, only minor to moderate adjustments and considerations are needed for the response and damage models. For instance, the finite element model must reflect the particular practices of the target country, e.g., details of connections and the resulting plastic hinge locations, the prevalent type of bracing, and the material properties. Another example is that there might be some nonstructural components that are prevalent in the target country, but not in the source country in which case, the fragility models for those components must be sought. Examples are presented in the application section of the present paper. However, the loss models need drastic adjustments as the consequences significantly depend on the local construction economy and design practices. The next section introduces the method proposed here to make such adjustments.

\section{$237 \quad 2.3$ Transferring Losses}

238 This section presents the method to transfer the four categories of losses. First, the repair cost is addressed, which significantly depends on the economy of the construction industry. Material, equipment, and labor costs vary significantly between countries, especially between developed countries with original seismic design codes and developing countries adopting codes. Consequently, adopting the repair costs of the former and merely converting those costs using the currency exchange rate leads to questionable results. On the other hand, developing new consequence functions for the latter would require a significant effort and is thus yet to be carried out for many such countries. 
Alternatively, the present paper proposes a practical approach to transfer these repair costs, which merely requires a few cost indicators. In this method, the repair cost of each component is broken into two parts: the first one comprises material and equipment costs and the second one consists of the labor cost. This disaggregation is considered because the extent to which these two parts vary between countries is markedly different, and thus they require different transferring methods. For example, the labor salary rates in a developing country, such as Iran, are significantly lower than those in the US, whereas there is a lower discrepancy in terms of material or equipment costs. The method is formulated as follows:

$$
C_{j, \mathrm{t}}^{\text {repair }}=C_{j, \mathrm{~s}}^{\text {repair }} \cdot\left[\frac{C_{\mathrm{r}, \mathrm{t}}}{C_{\mathrm{r}, \mathrm{s}}} \cdot\left(1-\frac{p_{\mathrm{L}, \mathrm{t}}}{100}\right)+\frac{r_{\mathrm{LS}, \mathrm{t}}}{r_{\mathrm{LS}, \mathrm{s}}} \cdot \frac{p_{\mathrm{L}, \mathrm{s}}}{100}\right]
$$

254

255

where the subscripts $t$ and s correspond to the values estimated for the target country and the source country, respectively. Also, $C_{j}^{\text {repair }}$ is the repair cost of the $j^{\text {th }}$ damage state, $C_{\mathrm{r}}$ is the replacement cost of the component, $p_{\mathrm{L}}$ is the share of the labor cost in percent, and $r_{\mathrm{LS}}$ is the labor salary rate. As seen, Eq. (8) adjusts the repair cost of the source country in each damage state by a factor that contains two terms. The first term scales the share of material and equipment costs by the ratio of the replacement cost of the component in the target and the source country. This ratio is readily obtainable through the cost catalog of the two countries. The second term scales the share of labor cost by the ratio of average labor salary rate. It is noted that the aforementioned values should be assessed for the same year in both the target and the source country. To transfer losses due to the downtime, local data on the rental, disruption, and owner occupancy rates need to be collected through field studies in which price quotes on rental costs and relocation expenses are solicitated.

In turn, transferring social losses requires the local values of the $V_{\mathrm{SL}}$. According to Cropper and Sahin (2009), $V_{\text {SL }}$ can be transferred from a source country to a target country using the following equation:

$V_{\mathrm{SL}, \mathrm{t}}=V_{\mathrm{SL}, \mathrm{s}} \cdot\left(\frac{Y_{\mathrm{t}}}{Y_{\mathrm{s}}}\right)^{e}$

where $Y$ is the gross domestic product (GDP) per capita and $e$ is the income elasticity of the $V_{\text {SL. }}$ Heger and Sarraf (2018) recommends the range of 1.0 to 1.4 for the income elasticity in the countries with low to moderate income levels. Finally, to transfer environmental losses, fees or taxes levied on the emission 
272 of carbon dioxide $\left(\mathrm{CO}_{2}\right)$ by the government of the target country must be used, if available. Otherwise,

273 the carbon fee is transferred here from a source country using the ratio of the initial construction cost of

274 the target country to that of the source country, as follows:

$275 f_{\mathrm{c}, \mathrm{t}}=f_{\mathrm{c}, \mathrm{s}} \cdot \frac{C_{o, \mathrm{t}}}{C_{o, \mathrm{~s}}}$

276 where $f_{\mathrm{c}}$ is the carbon fee. As will be shown later, environmental losses insignificantly impact the 277 lifecycle cost, and the optimal target reliability is nearly insensitive to this transfer.

\section{Application}

279 The methodology discussed above is implemented in this section to quantify the optimal reliability of 280 three midrise residential steel building archetypes. In the following, first these archetypes are introduced, 281 and then the implementation and results of each step of the methodology are presented and discussed.

\section{$282 \quad 3.1$ Design and Modeling}

283 The three archetypes are located in the City of Tehran, Iran, which is a highly seismically active region.

284 These archetypes all have the same plan with three bays in each direction and five stories as shown in 285 Fig. 1, but differ in the lateral load resisting systems. The first one has an IMF system in both directions, 286 the second one has a SCBF system in both directions, and the last one has an IMF system in the $\mathrm{x}$ 287 direction and a SCBF system in the y direction. Table 1 summarizes the properties of these archetypes. 288 The second and third column of this table present the structural systems of these archetypes in two 289 orthogonal directions. Characteristics of the material and cross-sections of these archetypes follow the 290 typical design and construction practices in Iran. In particular, the steel material used is the ST37 with a 291 yield stress of $235 \mathrm{MPa}$ and an ultimate stress of $363 \mathrm{MPa}$. Metal deck system with a slab thickness of $292140 \mathrm{~mm}$ is considered for all archetypes. Beams consist of both hot-rolled and built-up wide-flange 293 sections, columns consist of built-up hollow square sections (HSS) or built-up wide-flange sections, and 294 braces consist of double-UPN sections.

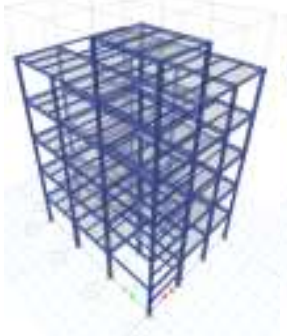

(a)

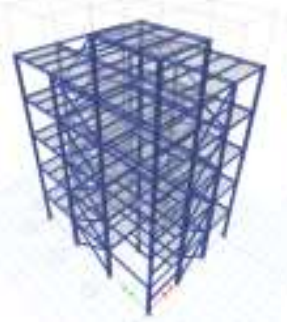

(b)

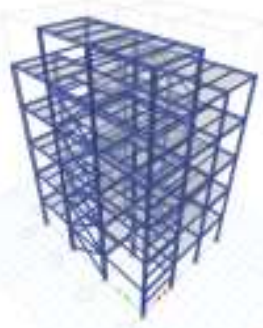

(c)

Fig. 1 Building archetypes: (a) IMF, (b) SCBF, and (c) IMF/SCBF 
Table 1 Characteristics of the building archetypes

\begin{tabular}{|c|c|c|c|c|}
\hline Name & $\begin{array}{l}\text { Lateral load resisting system } \\
\text { in } \mathrm{x} \text {-direction }\end{array}$ & $\begin{array}{l}\text { Lateral load resisting system } \\
\text { in y-direction }\end{array}$ & $\begin{array}{l}c_{\mathrm{s}, \text { code }} \\
\text { in X-direction }\end{array}$ & $\begin{array}{l}c_{\mathrm{s}, \mathrm{code}} \\
\text { in y-direction }\end{array}$ \\
\hline IMF & IMF & IMF & 0.111 & 0.111 \\
\hline SCBF & SCBF with $\mathrm{X}$ configuration & SCBF with $\mathrm{X}$ configuration & 0.126 & 0.126 \\
\hline $\mathrm{IMF} / \mathrm{SCBF}$ & IMF & SCBF with $\mathrm{X}$ configuration & 0.099 & 0.111 \\
\hline
\end{tabular}

298

299

300

301

302

303

304

305

306

307

308

309

310

311

312

313

314

315

316

317

318

319

320

321

322

323

The loading of these archetypes is according to Section 6 of the national building code of Iran (BHRC 2013a), which is adopted from ASCE/SEI 7-10 (ASCE 2010) regulations. The only major difference between the two is the design spectral acceleration, which is provided by the Iranian seismic code, known as Standard No. 2800, as the product of design PGA and spectral shape factor, which is a function of fundamental period of the structure and its site class. The resulting base shear coefficients of the three archetypes, $c_{\mathrm{s}, \mathrm{code}}$, are presented in the last two columns of Table 1 . The steel design of these archetypes follows Section 10 of the national building code of Iran (BHRC 2013b), which is adopted from AISC 360-10 (AISC 2010a) and AISC 341-10 (AISC 2010b). Such a vast adoption of seismic provisions is despite the fact that Iran has a higher seismicity compared to the US as nearly the entire area of the Iranian plateau lies on the seismic belt. In fact, the number of earthquakes with a moment magnitude above 7.0 since 1900 per unit area in Iran is 8.4 times higher than that of the US, and the number of such earthquakes per capita for Iran is 5.5 times higher than that of the US, in accordance with the data collected from USGS (2019). The seismicity of the region has a substantial impact on the optimal target reliability since the higher the seismicity, the more the weight of seismic losses in the total lifecycle cost (Gkimprixis et al. 2020). In addition, the reliability of the structures designed to Iranian codes are unknown as the load and resistance factors are not recalibrated based on the local design and construction practices when adopting the provisions. In fact, Mahmoudkalayeh and Mahsuli (2021) showed that the buildings designed to the Iranian building code fail to even meet the target reliability set by the original source codes, which emphasizes the prominent need for a calibration of the load and resistance factors at the very least when adopting the provisions.

In the present paper, each archetype is designed to different levels of base shear coefficient. The first level is obtained by the current code and corresponds to $\alpha=1$ per Eq. (1), i.e., the base building. The IMF archetype is designed to seven levels of base shear ranging from $\alpha=1$ to $\alpha=2.2$ with increments of 0.2 while the SCBF and the IMF/SCBF archetypes are designed to six levels of base shear ranging from $\alpha=1$ to $\alpha=2$. Each building is hereafter mentioned first by its archetypical category and then by the value of $\alpha$ to which it is designed; for example, IMF1.2 represents the IMF archetype designed to $\alpha=1.2$. 
Attention is now turned to the nonlinear modeling of the building archetypes. To assess the response of structures to seismic excitations, nonlinear dynamic analyses are performed on analytical models which are able to capture the nonlinear behavior of structural components. In the present paper, a detailed 3D nonlinear finite element model is developed in OpenSees (Mckenna 1999). For a risk analysis to be comprehensive, the response of structures should be assessed with acceptable precision from low levels of seismic demands causing insignificant damages up to severe demands triggering collapse. Since under such severe levels of demand, there is a high degree of inelasticity and deterioration in structural components, robust numerical models are required to assess the response (FEMA 2018a). As such, the nonlinear model developed herein is validated to ensure its robustness in the supplementary document. In what follows, the details of the model are elaborated.

Fig. 2 depicts the nonlinear model developed herein. As shown in Fig. 2(a), beams and columns are modeled using the lumped plasticity method, in which the element itself is elastic and the nonlinearity is captured by concentrated-plasticity rotational springs at the two ends of the member (Zareian and Krawinkler 2009). Bilinear hysteretic moment-rotation diagrams define the behavior of these springs (Lignos and Krawinkler 2010, 2011; NIST 2017; Lignos et al. 2019). In the present paper, the modified Ibarra-Medina-Krawinkler (IMK) model (Ibarra et al. 2005) is employed for such purpose. This model is able to capture the deterioration both in strength and in stiffness (Krawinkler and Zareian 2007; Krawinkler et al. 2010). The rotational springs are located where the formation of plastic hinges is expected. In moment frames, this happens at the ends of the flange plates used for rigid beam-to-column connections according to AISC 358-10 (AISC 2010c). Similarly, in braced frames, the hinges are expected at the ends of the gusset plates used as the connectors per Karamanci (2013). These connections are the prevalent types of connection in the Iranian design practice. Also, a pinching behavior is considered for beam-to-gusset connections through the pinching IMK model (Stoakes and Fahnestock 2011; Lignos and Krawinkler 2013; Karamanci and Lignos 2014). Since simple connections have a markedly lower strength and stiffness compared to moment frames and braced frames, their strength and stiffness is ignored in the model, and the corresponding springs are placed at the face of the adjacent columns as shown in Fig. 2(b).

Panel zones are modeled using the Joint 3D element in OpenSees (Altoontash 2004), and their shear 352 behavior is captured by a rotational spring in the middle of this element based on the model presented 
by Kim et al. (2015). As shown in Fig. 2(c), braces are modeled using fiber elements as proposed by 354 Uriz and Mahin (2008). This model is able to account for the interaction of the axial load and the second order bending moment as well as the low-cycle fatigue behavior. The buckling of braces is modeled through an imperfection with a maximum value of $0.1 \%$ of the length of the element in its middle as suggested by Karamanci and Lignos (2014). Moreover, the out-of-plane behavior of the gusset plate is modeled through a rotational spring following a stiffening elastoplastic behavior per Hsiao et al. (2012).

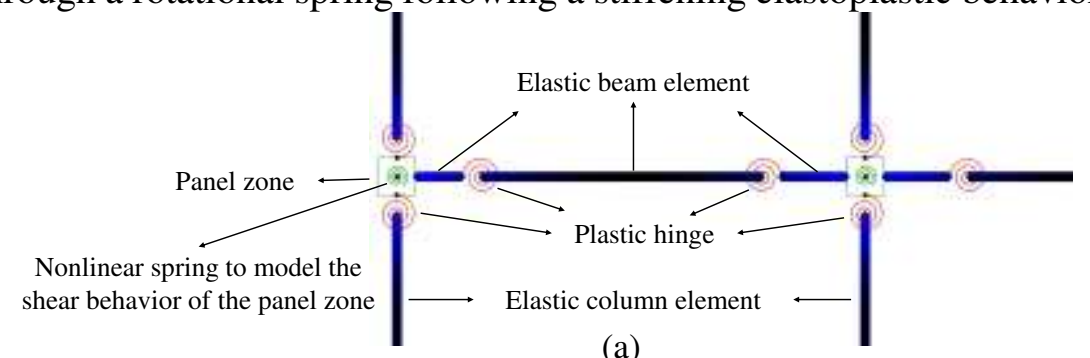

(a)

(b)

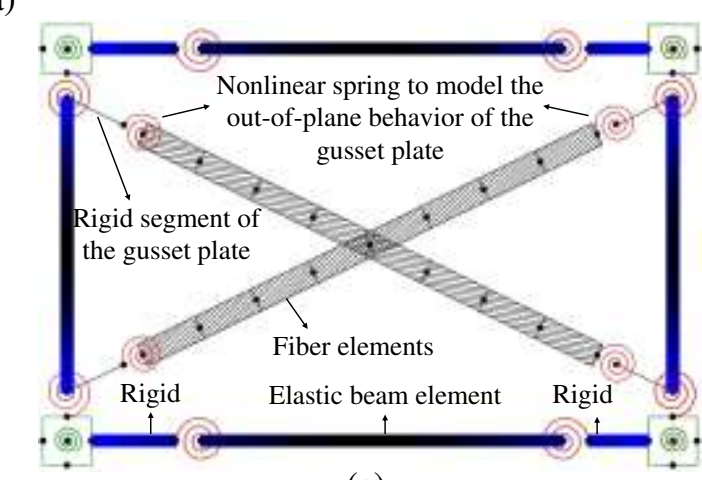

(c)

Fig. 2 Details of the nonlinear model: (a) rigid beam-to-column connection of moment-resisting frames, (b) simple beam-to-column connection, and (c) braced frames

Rayleigh damping is employed to capture the inherent damping of the structure, and its coefficients are adjusted to achieve a damping ratio of $2 \%$ at $20 \%$ and $150 \%$ of the fundamental period, which is the vibrational period range of interest (Lignos et al. 2011, 2013; Karamanci and Lignos 2014). The Rayleigh damping coefficients are recomputed in each step of the analysis to avoid overestimating the collapse capacity due to the initial stiffness approximation (Zareian and Medina 2010; Karamanci and Lignos 2014). More details about the analytical model developed herein are presented in the Tables S1 through S6 and Fig. S3 through S7 of the supplementary document.

\subsection{Initial Construction Cost Evaluation}

The initial construction cost of the three archetypes is evaluated per the method presented in the preceding section and the results are shown in Fig. 3 and Fig. 4 for the IMF and the SCBF archetypes.

372 Fig. 3(a) and (b) show for the IMF and the SCBF archetypes the structural construction cost divided by 
373 the total construction cost and its disaggregation to the cost of elements of the lateral load resisting 374 system and elements that only belong to the gravity system. As this figure shows, the share of the 375 structural construction cost expectedly increases when the buildings are designed to higher base shear 376 coefficient. For the base building of the IMF archetype in which all of the beams and columns are parts 377 of the lateral load resisting system, the contribution of structural costs to the total construction cost is 378 about $22 \%$. From this contribution, $20 \%$ is attributed to the elements of the lateral load resisting system 379 and the other $2 \%$ to the elements only bearing the gravitational loads. For the SCBF archetype, Fig. 3(b) 380 shows that the structural cost contribution at $21 \%$ is almost the same as that of the IMF archetype, but 381 the $12 \%$ contribution of the lateral load resisting system is significantly lower. The underlined reason is 382 that in this archetype, only the beams and columns connected to the braces and the braces themselves 383 are parts of the lateral load resisting system. For the IMF/SCBF archetype, whose results are omitted 384 here for brevity, the contribution of the construction cost of the structural elements is $19 \%$, of which $38514 \%$ is attributed to the lateral load resisting system. The rather low share of structural costs in the total 386 construction cost is attributed to the high cost of nonstructural components as is also indicated by the 387 literature (FEMA-NIBS 2012; Gkimprixis et al. 2020). The construction costs that are evaluated for the 388 three archetypes in this paper were also validated by the data gathered from a survey on buildings that have recently been constructed in Tehran.

Fig. 4(a) and (b) demonstrate the total initial construction cost of the IMF and the SCBF archetypes at different design base shear levels normalized to the initial construction cost of the base building. These 392 figures also show the share of the elements of the lateral load resisting system. It is observed in this 393 figure that by multiplying the design base shear by a factor of two, the cost of the lateral load resisting 394 system is not doubled but increases by $40 \%$ and $24 \%$ for the IMF and the SCBF archetypes, respectively.

395 The underlying reason is twofold. First, the earthquake load contributes to only a portion of the design 396 load combinations. As such, when doubling the earthquake load, the ultimate demand on structural 397 elements would be less than doubled. Second, the initial construction cost of structural elements has a 398 linear relationship with their dimensions, while the strength and stiffness of these elements depend on 399 such geometric properties as the plastic section modulus and the moment of inertia, which respectively 400 increase quadratically and cubically with the cross-section dimensions. Consequently, even at $\alpha=2$, the 401 total initial construction costs of the IMF and the SCBF archetypes in Fig. 4(a) and (b) increase by $8 \%$ 
402

403

404

405

406

407

408

409

410

411

412

413

414

415

416

417

418

419

and 3\%, respectively. This indicates the relatively insignificant effect of such a change on the construction cost. The same conclusion has been drawn in past studies, such as Gkimprixis et al. (2020),

NIST (2013), and FEMA P-2082 (FEMA 2020) among others.

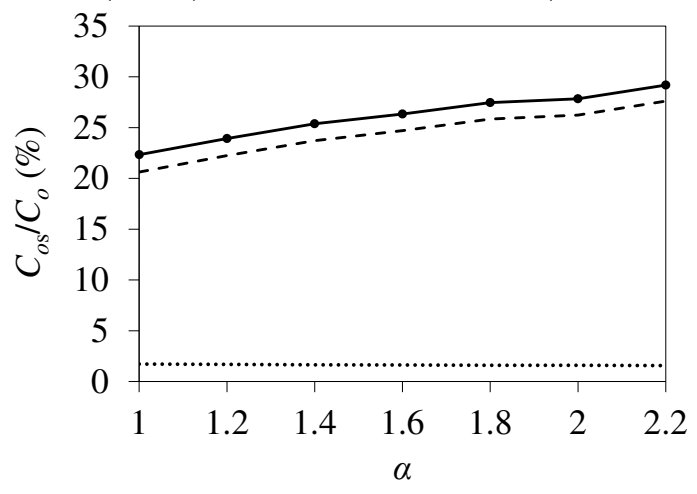

(a)

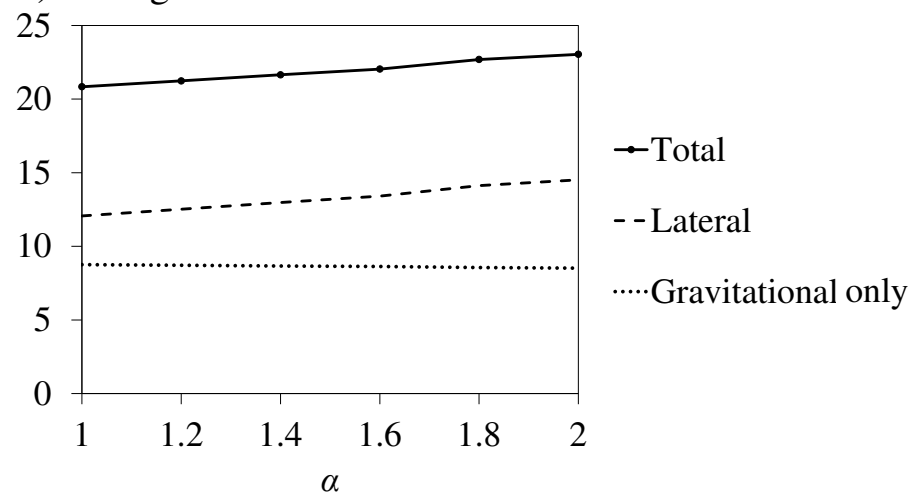

(b)

Fig. 3 Contribution of the structural construction cost to the total construction cost for (a) the IMF and (b) the SCBF



(a)

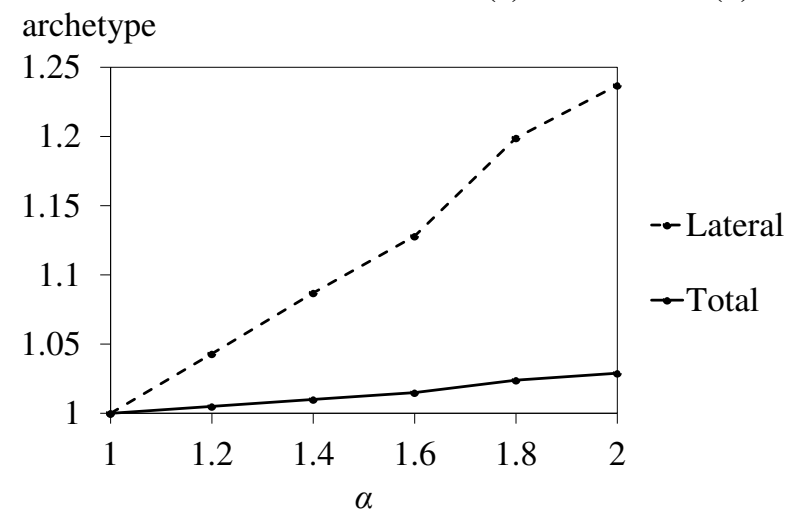

(b)

Fig. 4 Initial construction cost at different levels of design base shear normalized to the construction cost of the base building for (a) the IMF and (b) the SCBF archetype

\subsection{Detailed Risk Analysis}

This section presents the results of the detailed risk analysis of the building archetypes starting with hazard results followed by response, damage, and loss results.

\subsubsection{Hazard}

The hazard analysis is conducted here for 24 natural periods in the range of $0.6 \mathrm{~s}$ to $2 \mathrm{~s}$ using scenario sampling (Rahimi and Mahsuli 2019). Both area and line sources in a $150 \mathrm{~km}$ radius of the location of the building archetypes are considered for the analysis. These sources are depicted in Fig. 5 and their parameters are defined and presented in Tables S7 through S9 of the supplementary document. The seismic sources and their properties are adopted from Askari and Mahsuli (2020). Fig. 6 shows the 
results of the hazard analysis in terms of the non-exceedance probability of PGA and $\mathrm{Sa}$ at several natural

421 periods. These curves will be used later to compute the total loss exceedance probabilities.

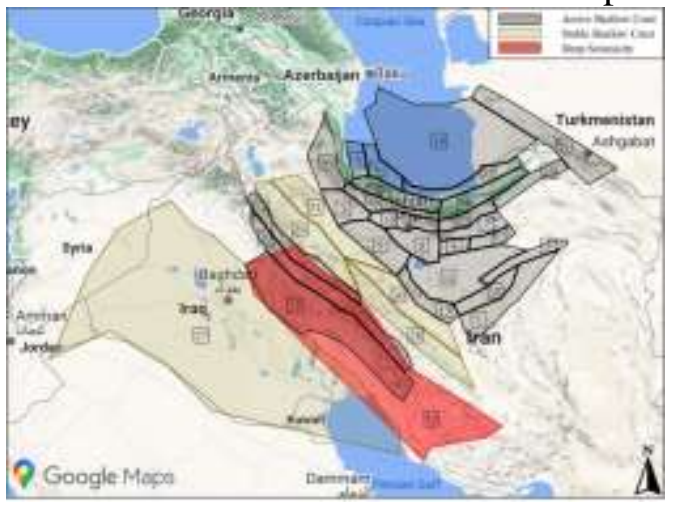

(a)

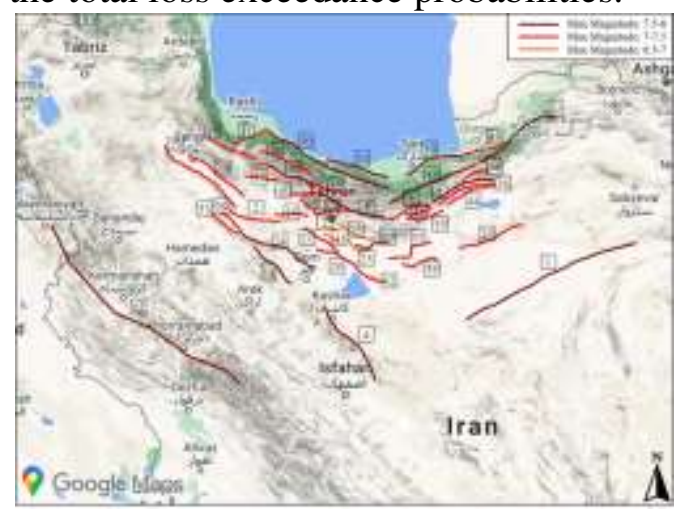

(b)

Fig. 5 Seismic sources in the case study: (a) area sources and (b) line sources (Askari and Mahsuli 2020)

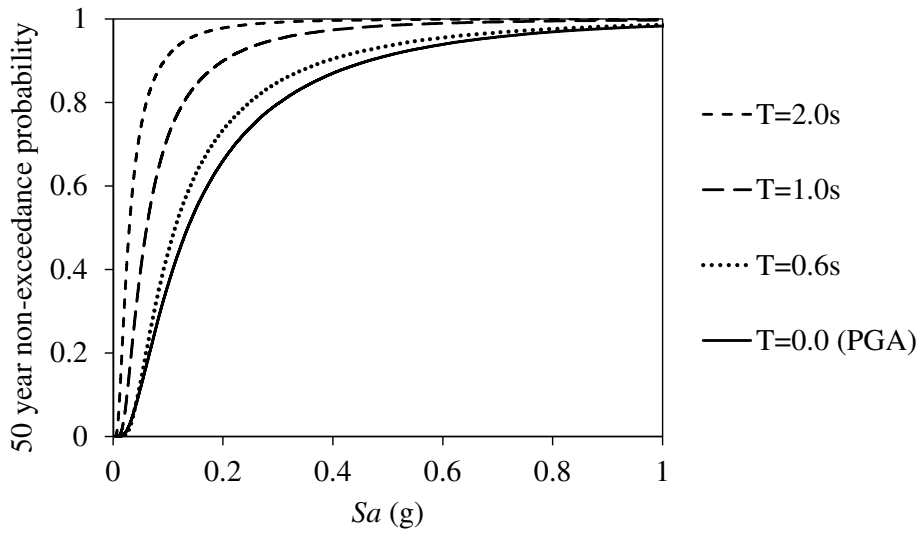

Fig. 6 Hazard curves

\subsubsection{Response}

427 To evaluate the response of the buildings under seismic excitation, IDA is conducted on the models 428 introduced in Section 3.1 subject to the 22 pairs of ground motion records of FEMA P695 (FEMA 2009).

429 The horizontal components are also swapped once to create 44 pairs of ground motion. Both horizontal 430 components of these records as well as the vertical component are applied simultaneously to the 3D analytical models developed herein, as inclusion of the vertical component in the analyses may 432 significantly impact the reliability of structures (Fayaz and Zareian 2019). As such, a total of 44 IDAs 433 are conducted for each of the design base shear levels of each archetype with 15 increments of the 434 intensity measure amounting to $12,5403 \mathrm{D}$ nonlinear dynamic time-history analyses with the CPU time 435 of more than 3000 hours. Therefore, parallel processing is employed to make the analytical computations feasible. The results are presented and discussed in the following. 
and discussed. Fig. 7 shows the maximum inter-story drift ratio given the 5\% damped spectral acceleration at the fundamental period for the base building of each of the three archetypes. In this figure, the results of each one of the 44 IDAs alongside their $16^{\text {th }}, 50^{\text {th }}$, and $84^{\text {th }}$ percentiles are depicted. From these curves, the softening and ultimately the collapse of the structures can be traced. It is also evident that the SCBF archetype is the most robust and least ductile between the three as its collapse occurs at 443 higher levels of the strength demand and lower values of the drift. This is owing to the higher lateral stiffness of the braced frames compared to that of the moment frames.

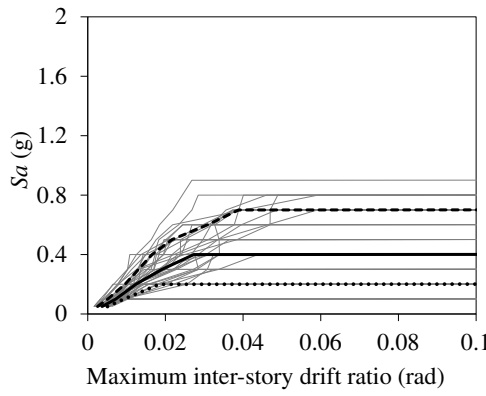

(a)



(b)



(c)

Fig. 7 IDA curves of (a) IMF1, (b) SCBF1, and (c) IMF/SCBF1

447

Next, the conditional probability of collapse given the intensity measure, known as the collapse fragility, is presented and discussed. Fig. 8 shows these curves for the three archetypes in three values of $\alpha$. To assess the total probability of collapse of the buildings, the collapse fragility curves need to be integrated over the hazard curves. Fig. 9 shows the 50-year collapse probability of the three archetypes. As observed, while the conditional collapse probability of IMF2 given $S a$ is lower than that of IMF1.4, its 50-year collapse probability is higher. This is on account of the fact that increasing the design base shear also increases the lateral stiffness of the buildings and thus, the fundamental period decreases. As observed in Fig. 6, this, in turn, results in higher exceedance probabilities for a given value of $\mathrm{Sa}$, which would increase the seismic risk. In other words, while the building is made stronger, it is subjected to a higher demand (Tesfamariam et al. 2014). These two counteract each other and may result in a higher collapse probability as is the case for IMF1.4 and IMF2.



(a)

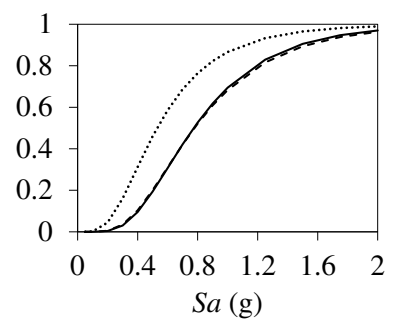

(b)



(c)

Fig. 8 Collapse fragility curves for (a) the IMF, (b) the SCBF, and (c) the IMF/SCBF archetype 


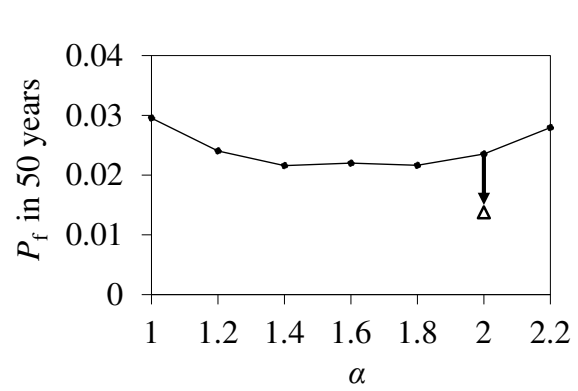

(a)

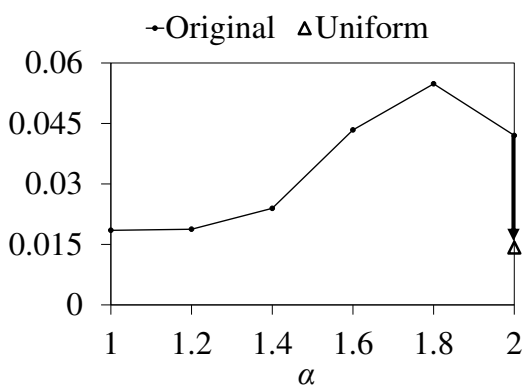

(b)

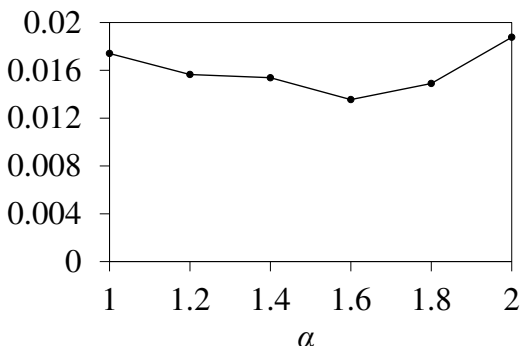

(c)
460

461

462

463

464

465

466

467

468

469

470

471

472

473

474

475

476

477

478

479

480

481

482

483

484

Fig. 9 50-year collapse probability of (a) the IMF, (b) the SCBF, and (c) the IMF/SCBF archetype

Moreover, Fig. 8 shows that increasing $\alpha$ expectedly decreases the conditional collapse probability of the IMF and the IMF/SCBF archetypes. For the SCBF archetype, however, not only increasing $\alpha$ leads to no improvement of the collapse capacity, but it increases its conditional collapse probability. This combined with the increased demand on the structure results in markedly higher probabilities of collapse for SCBF1.6 to SCBF2 as shown in Fig. 9(b). As such, Fig. 9 entails an important insight: the collapse probability does not always decrease with increasing the design base shear. In other words, increasing the building strength, in some cases, may lead to a higher collapse probability, which may seem counterintuitive at first. However, close inspection of the distribution of building responses among various stories reveals the underlying reason. The collapse of a building is in many cases due to local story mechanisms caused by the concentration of plastic deformations in one or more stories (Karami Mohammadi et al. 2004; Karamanci and Lignos 2014). Such a concentration usually occurs in stories that are relatively softer and/or weaker along the height. As such, the collapse mechanism is heavily contingent upon the distribution of the lateral stiffness and strength along the height of the building.

For further assessment, Fig. 10 displays the distribution of the lateral strength along the height of the IMF and the SCBF archetypes for several values of $\alpha$. As observed in Fig. 10(a), the top two stories of IMF1 and IMF2 are markedly weaker than the first three stories. For instance, the lateral strength of the fourth and the last story of IMF2 respectively decreases by $30 \%$ and $71 \%$ relative to the average strength of the first three stories. This makes the two top stories prone to the concentration of plastic deformations and ultimately, to the local collapse. Fig. 11 demonstrates the probability that the maximum inter-story drift ratio occurs in each story of the IMF and the SCBF archetypes at the median collapse capacity for various $\alpha$ values. The higher the probability for a story, the more likely it is that plastic deformations are concentrated in that story. According to this figure, plastic deformations are concentrated in the fourth story of IMF1 and the last story of IMF2, which were previously shown in 
Fig. 10(a) to be relatively weaker and softer along the height. To better illustrate this phenomenon, an alternative design is considered here for IMF2. For this alternative design, the distribution of the lateral stiffness and strength along the height are adjusted to avoid a significant reduction in top stories and achieve a more uniform distribution. Hence, this design is labeled as IMF2U hereafter, in which the letter "U" signifies a more uniform distribution. As observed in Fig. 10(a), IMF2U has a markedly less dispersed strength distribution along the height. As a result, and as shown in Fig. 11, it is now notably less likely for the maximum inter-story drift ratio to occur in the last story and there is a notable share for two other stories which indicates a more uniform distribution of plastic deformations. This allows the structure to take full advantage of its higher strength and stiffness. This is evident in Fig. 9(a) in which the collapse probability of IMF2U is $41 \%$ and $53 \%$ lower than those of IMF2 and IMF1, respectively.

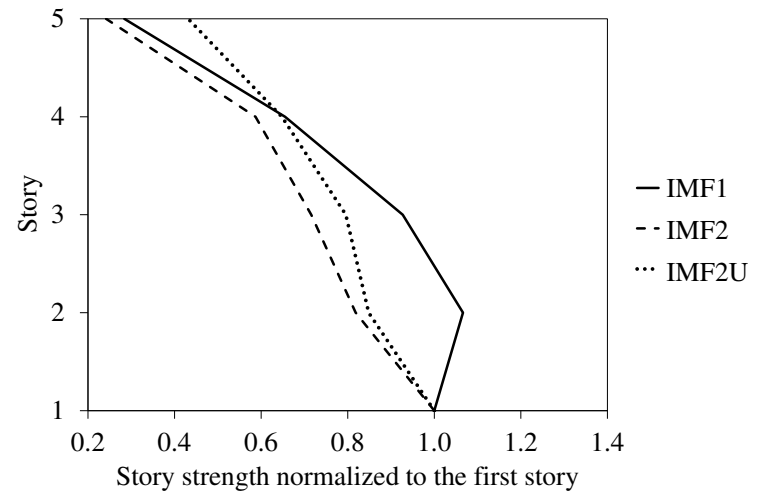

(a)

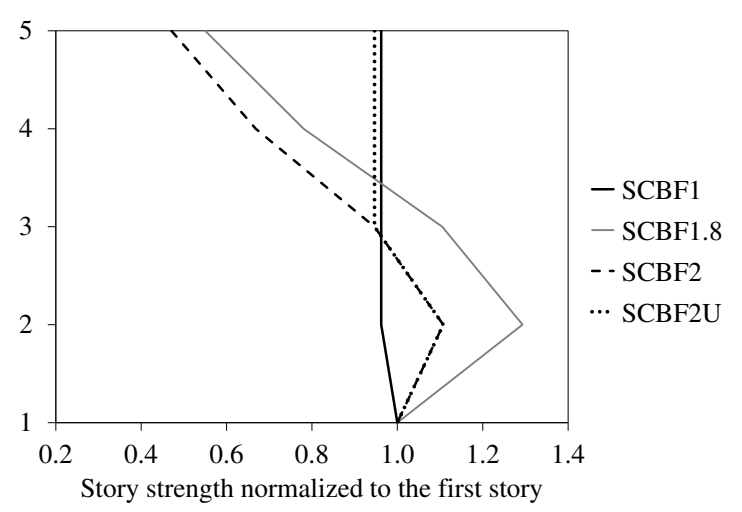

(b)
496 498

Fig. 10 Vertical distribution of the lateral strength of various stories normalized by the strength of the first story for (a) the IMF and (b) the SCBF archetype

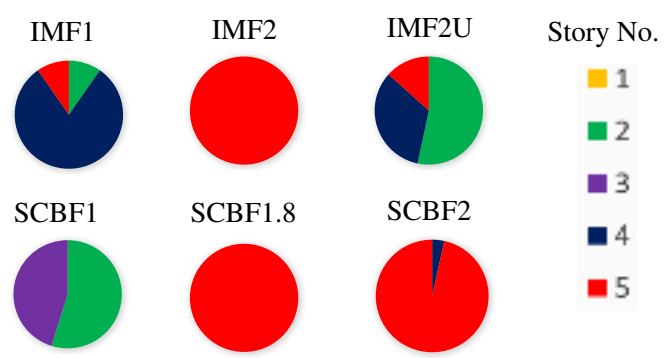

Fig. 11 The probability that the maximum inter-story drift ratio occurs in different stories of the IMF and the SCBF archetypes at the median collapse capacity

The same result also holds for the SCBF archetype. As observed in Fig. 10(b), the dispersion of the lateral strength distribution of SCBF1.8 and SCBF2 along the height is markedly higher than that of SCBF1. Specifically, the lateral strength of the last story of SCBF1.8 is $51 \%$ lower than the average strength of the first three stories. As shown in Fig. 11, this causes concentration of plastic deformations 
in the last story. This, in turn, results in a significant increase in the collapse probability of SCBF1.8 and SCBF2 in Fig. 9(b). Again, an alternative design is considered for SCBF2 with a more uniform distribution of strength and stiffness along the height, which is denoted by SCBF2U, as shown in Fig. 10(b). As observed in Fig. 9(b), the collapse probability of SCBF2U decreases by $66 \%$ compared to SCBF2 and by $23 \%$ compared to SCBF1. The increase in the collapse probability due to nonuniformity for SCBF2 is markedly higher than that of IMF2. This is owing to the fact that a high demand on a single story of SCBF buildings would lead to buckling or yielding of the braces of that story, which incapacitates the lateral load resisting system at that story and ultimately, leads to local collapse (Karamanci and Lignos 2014).

Another notable insight here is that whereas the first story of SCBF1.8 is a weak story according to ASCE/SEI 7-10 as its lateral strength decreases by more than $20 \%$ compared to its upper story, the deformations are concentrated in the last story. This shows that the design codes are overly conservative on the regulations related to the formation of a weak/soft story at the bottom, as was also noted by FEMA P-2012 (FEMA 2018c). However, the design codes have adopted no measure to prevent the formation of a weak/soft story at the top, a phenomenon which is shown here to severely impacts the collapse capacity.

The distribution of the lateral stiffness and strength along the height of buildings is the result of the height-wise relationships proposed by the seismic design codes for vertical distribution of the design base shear. These relationships are based on the elastic behavior of the structure and are not optimal when the structures undergo significant inelastic deformations (Karami Mohammadi et al. 2004). As observed above, this may prevent the buildings from using their full capacity. This conclusion corroborates the results of previous studies that demonstrates the current distribution of the lateral strength yields to markedly uneven ductility capacities between stories (Chopra 1995; Moghaddam and Esmailzadeh Hakimi 1999; Karami Mohammadi et al. 2004). In fact, it has been observed that usually the ductility capacity at the top stories are smaller (Karami Mohammadi and Sharghi 2014).

It has thus far been shown that increasing the design base shear may lead to a higher collapse 532 probability, which is caused by a higher dispersion of strength and stiffness distribution along the height. 533 The reason behind this higher dispersion is that the current practice leads to designs in which the average 534 demand-to-capacity of structural members would, in general, decrease along the height. In other words, 
the structural members at the bottom stories are closer to the limit state than the structural members at the top stories. This is mainly because there is a lower bound for the cross-section of structural members in practice. For instance, the smallest steel profile that is used for bracing in Iran is UPN 80, which is an overdesign for the bracings at the top stories of SCBF1. Therefore, increasing the earthquake design force leads to larger cross-sections for structural members at the lower stories and nearly no change at the higher stories as the structural members only near their limit states. This, in turn, increases the dispersion of the lateral stiffness and strength distribution as is the case for the SCBF archetype in Fig. 10(b). If a cross-section smaller than the said practical lower bound had been used for bracings at the top stories at $\alpha=1$, a similar high dispersion of stiffness and strength distribution would have been observed and the probability of collapse of the base building would have significantly increased. All in all, there is a significant potential for improving the vertical distribution of the design base shear in seismic codes.

\subsubsection{Damage and Loss}

548 The next step is the damage and the loss analyses. For this purpose, damage fragilities and loss models 549 for some of the structural and nonstructural components are adopted from the literature. Many of these components are modeled using the models proposed by FEMA P-58 (FEMA 2018d) which have been developed for steel structures in the US. Since the seismic codes used for designing the building archetypes are adopted from ASCE/SEI 7-10, AISC 360-10, and AISC 341-10, these damage fragility models can also be employed to predict the performance of the buildings. However, some of the nonstructural components that are prevalent in the Iranian construction practice are not available in FEMA P-58. Examples are masonry infill walls and masonry façades, for which fragility models proposed by Cardone and Perrone (2015), De Risi et al. (2018), and Khalili (2019) are adopted. These fragility curves are depicted in Fig. S8 of the supplementary document.

As mentioned previously, contrary to damage models, the loss models presented by FEMA P-58 need drastic adjustments to be applicable to the building archetypes. As such, the losses are transferred

560 from the US to Iran using the approach presented in Section 2.3. To highlight the error that arises by converting the final monetary values using the currency exchange rate, Fig. 12 is presented. This figure shows the ratio of the replacement cost of some components as suggested by the FEMA P-58 technical manuals for the US, further converted to the Iranian Rial, to the replacement cost of the same components 
evaluated employing Iranian cost catalogs (CPBO 2019). In this figure, subscript US represents the

565

566

567

568

569

570

571

572

573

574

575

576

577

579

580

581

582

583

584

source country and subscript IR represents the target country, Iran. The comparison is made based on the costs at the beginning of 2019, i.e., the exchange rate is taken as 130,000 Rials per US dollar, and the Iranian cost catalog belongs to that year. It is observed from Fig. 12 that for such components as masonry parapets and ceramic tiles, the error is significant and the cost is overestimated by up to 30 times, as the labor cost markedly contributes to the total repair or replacement cost of these components. However, for such components as elevators or chillers, the error is small because the share of material and equipment costs are dominant in the repair or replacement cost of these components. The dominant effect of the labor on this cost stems from the significant difference in salary rates in Iran and the US, which are respectively $\$ 0.8$ and $\$ 17.3$ per hour (BLS 2019; CPBO 2019). This figure reemphasizes the need to employ the proposed loss transfer method when conducting risk analysis in developing countries using the likes of FEMA P-58 approach, especially for the countries with a significant different labor cost and for the components whose repair effort is rather labor-intensive.
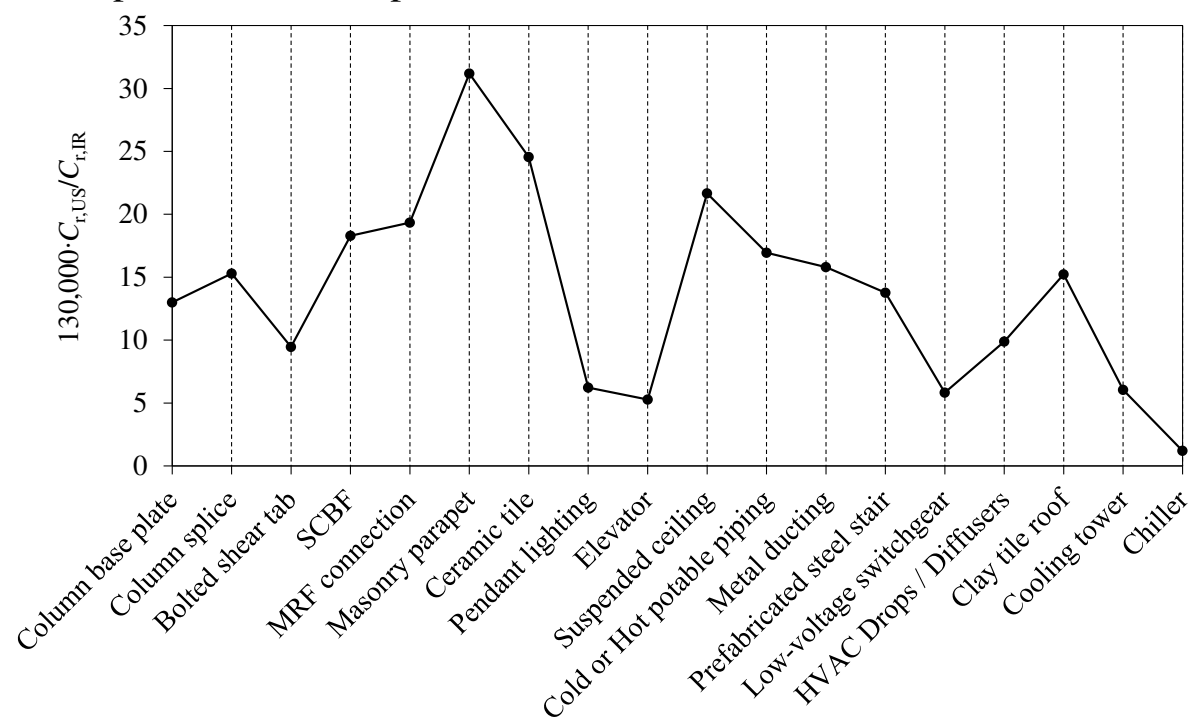

Fig. 12 Comparison of the replacement cost of some components between Iran and the US

In the following, the results of the risk analysis of the building archetypes are presented. To evaluate the monetary values associated with indirect economic losses, rental, owner occupancy, and disruption rates presented by Zibaei and Mahsuli (2021) for Iran are adopted. To evaluate the social losses, the value of a statistical life for Iran is estimated at \$504,900 per Eq. (9) (Heger and Sarraf 2018). In addition, the morbidity fraction is taken as $16.5 \%$ based on the recommendations made by Cropper and Sahin (2009) for the costs of treating the injury severity levels of II and III of FEMA-NIBS (2012), i.e., major 
and life-threatening injury levels. Finally, Wang et al. (2019) estimated the median environmental loss per metric ton of $\mathrm{CO}_{2}$ as $\$ 30.8$. This rate is here transferred using Eq. (10) in which the construction costs in Iran and the US are respectively obtained from IRCEO (2019) and FEMA-NIBS (2012). To compute the losses due to energy use, each Megajoule of embodied energy is taken as equal to 98 grams of emitted $\mathrm{CO}_{2}$ according to CSIRO (2006).

Fig. 13 shows the share of each one of the four above-mentioned categories of losses for IMF1 and IMF1.8. According to this figure, social losses have the highest share of the total loss, owing to the significant loss imposed on the society by every death toll or serious injury, an observation that is in line with previous studies (Gudipati and Cha 2019; Gkimprixis et al. 2020). After social losses, direct economic losses have the highest share, whereas indirect economic and environmental losses insignificantly contribute to the total seismic loss. As expected, the lower the probability of collapse, the lower the share of social losses and the higher the share of direct economic losses, as is shown in Fig.

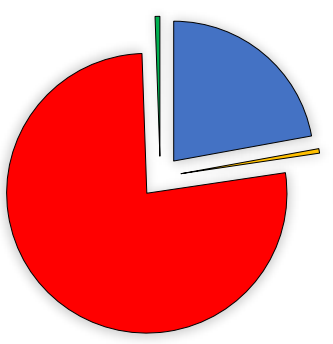

(a)

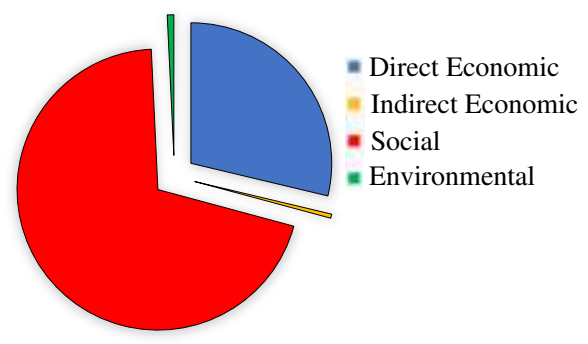

(b)

Fig. 13 Share of the four categories of losses for (a) IMF1 and (b) IMF1.8

Fig. 14 demonstrates the expected total loss of various building archetypes at different design base shear levels, normalized to the expected total loss of the base building. This figure also shows the disaggregation of the expected total loss into the four categories of loss. According to this figure, social and indirect economic losses follow the same trend as they are both governed by the collapse probability. The social losses are governed by the collapse probability because major casualties occur in the event of collapse (Ansal et al. 2009). Likewise, the indirect economic losses are governed by the collapse probability because the repair time of structural and nonstructural components are generally very short compared to the replacement time of an entire building in the event of collapse. On the other hand, direct economic losses and environmental impacts follow the same trend that differs from the other two loss categories. These trends are most evident in Fig. 14(c), which shows that increasing the design base 
610 shear leads to lower social and indirect economic losses as a result of a smaller collapse probability. On

611 the contrary, increasing the design base shear leads to higher direct economic losses and environmental

612 impacts, owing to the fact that a larger lateral stiffness due to a higher design force results in larger floor

613 accelerations, and that the direct economic loss is generally controlled by the failure of nonstructural

614 acceleration-sensitive components such as elevators, chillers, and piping, and the out-of-plane failure of

615 infill walls.

616 In summary, increasing the design base shear affects various categories of loss differently. Hence,

617 accounting for the full range of damage, and not only collapse, as well as comprehensive modeling of

618 consequences is paramount when trying to determine the optimal target reliability based on the minimum

619 lifecycle cost. In other words, the current practice of merely focusing on the life-safety limit states leads

620 to suboptimal levels of reliability, and lacks the required holistic point of view (Gudipati and Cha 2019).

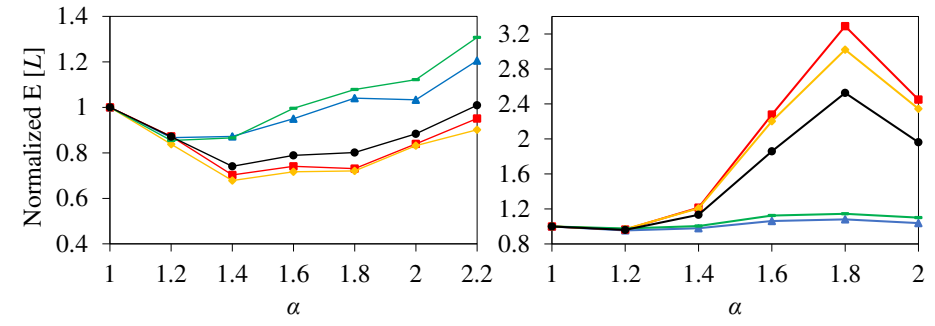

(a)

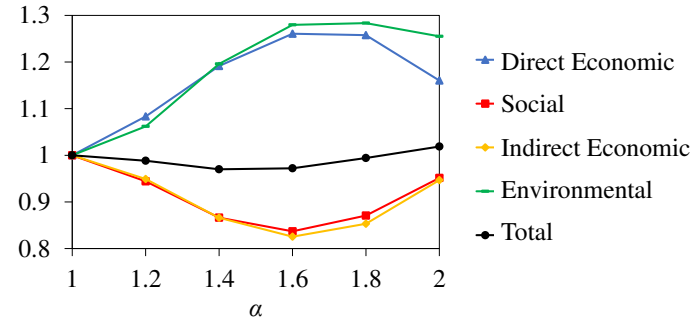

(c)
621

623

624

625

626

627

628

629

630

631

632

633

634

635

Fig. 14 Expected losses normalized to the corresponding value of the base building for (a) the IMF, (b) the SCBF, and (c) the IMF/SCBF archetype

\subsection{Target Reliability Quantification}

This section evaluates the expected lifecycle cost of the building archetypes as the sum of the initial construction costs and the expected total seismic losses for various design base shear levels. It then determines the optimal design base shear and the resulting target reliability based on the minimum lifecycle cost. Fig. 15 depicts the expected annual lifecycle cost of the building archetypes at different design base shear levels normalized to that of the base building against $\alpha$. It is observed in this figure that for the IMF/SCBF archetype, the lifecycle cost insignificantly varies with the design base shear as the savings due to lower losses are counteracted by nearly the same amount of the higher construction cost. In contrast, the lifecycle cost increases with the design base shear for the SCBF archetype as both the construction costs and seismic losses increase. As discussed previously, the increase in the seismic losses is caused by the increase in the dispersion of the lateral strength and stiffness distribution along the height. As such, no increase in the prescribed design base shear of the seismic design code is 
636 advisable for the IMF/SCBF and the SCBF archetypes.

637

638

639

640

641

642

643

644

645

646

647

648

649

650

651

652

653

654

655

656

657

658

659

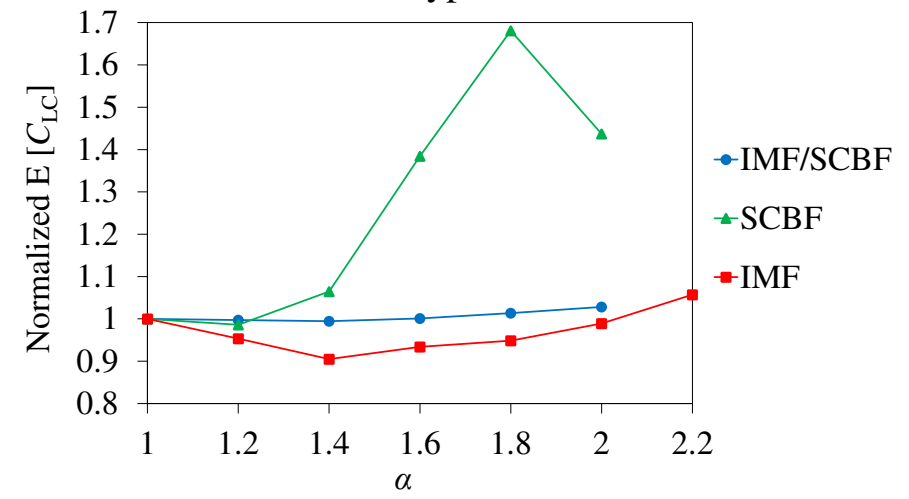

Fig. 15 Normalized expected annual lifecycle cost of the three building archetypes against $\alpha$

For the IMF archetype, however, Fig. 15 shows that the optimum design base shear at $\alpha=1.4$ differs from the status quo. This indicates a need for a higher prescribed strength for the IMF archetype. At $45 \%$, this archetype also has the highest share of seismic losses in the lifecycle cost amongst the three considered archetypes. The calibration of the prescribed strength could be implemented in the response modification factor. Such calibration to achieve the target reliability has precedents in the literature (FEMA 2009; Bezabeh et al. 2017; Tesfamariam et al. 2021). Calibrating the response modification factor according to the results shown in Fig. 15 would give its optimal value as 3.5 for the IMF archetype. With such a change, the expected annual lifecycle cost of the IMF buildings would be reduced by $10 \%$. This reduction may not be fully appreciated unless taken into the scale of a city such as Tehran, which has over 2,850,000 residential buildings (CUS 2020), out of which it is estimated that roughly 220,000 are steel IMF buildings (Mahsuli et al. 2018; SCI 2021). The 10\% reduction in the lifecycle cost of this many buildings amounts to $\$ 500$ million lifetime savings, which will significantly increase if the entire country is considered. It is noted that generalizing the results for the entire steel IMF category requires further analyses on more archetypes in future research.

Using the results above, the optimal target reliability for the three archetypes is quantified next. Fig. 16(a) and (b) depict the expected annual lifecycle cost of the building archetypes at different design base shear levels normalized to that of the base building against their 50-year reliability indices and the collapse probabilities given MCE, respectively. The points that correspond to the current and the optimal designs are indicated by arrows in these figures. As Fig. 16(a) shows, the 50-year optimal target reliability index for the IMF archetype is 2.0 , which corresponds to a collapse probability given MCE of $16 \%$ per Fig. 16(b). For the other two archetypes, the 50-year optimal target reliability index is 2.1, 
660 which corresponds to the optimal collapse probability given MCE of 16\%. The resulting collapse 661 probabilities here are consistent with those obtained by Gudipati and Cha (2019), which also concluded 662 that the $10 \%$ threshold prescribed by ASCE/SEI 7 is somehow stringent.

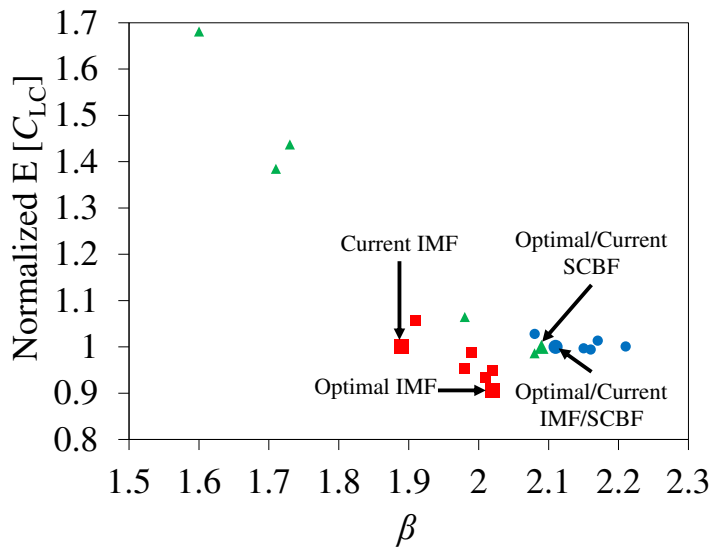

(a)

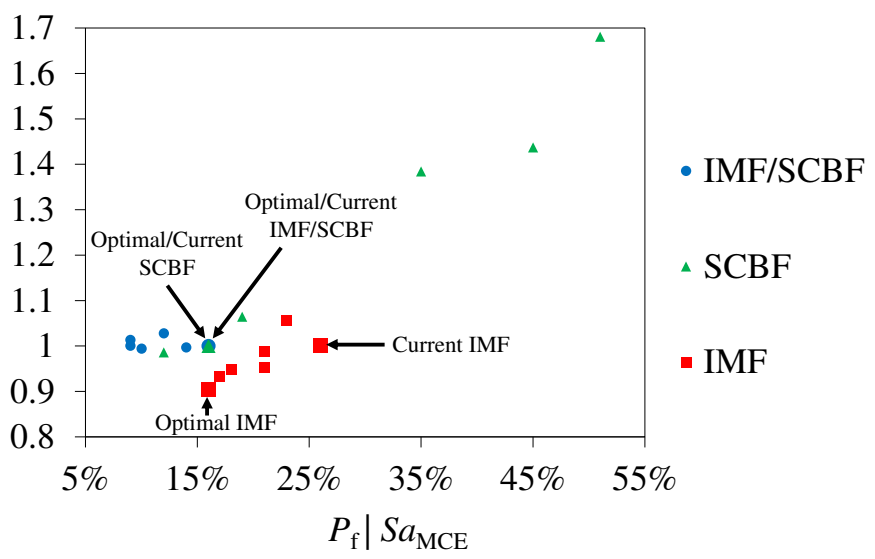

(b)
663

664

665

666

667

668

669

670

671

672

673

674

675

676

677

678

679

680

681

682

Fig. 16 Normalized expected annual lifecycle cost of the three building archetypes against (a) the reliability index and (b) the collapse probability given MCE

\section{Conclusion}

The target reliability levels against which seismic regulations are calibrated are commonly determined through accepted practice, which is neither objective, nor optimal. The issue is exacerbated for many countries that adopt their standards from original codes, especially when those countries do not recalibrate the adopted provisions according to their local conditions. This paper presents a methodology to quantify the optimal target reliability based on detailed risk analysis. This methodology requires a library of risk models, which are only available for a few countries, and developing these models anew for other countries is a rather demanding task, and an obstacle that impedes quantification of the target reliability based on the local construction industry and design practices. To remedy, a method is introduced in this paper to adjust the available risk models using a few readily-available cost indicators. Hence, the proposed methodology not only calibrates the adopted provisions based on the local construction industry, but also leads to risk-optimal calibration through quantification of the optimal target reliability based on the minimum lifecycle cost.

The proposed methodology is applied to the national building code of Iran, which is adopted from the building codes of the US with no recalibration. The application features a case study of three midrise residential steel building archetypes with various structural systems including IMF, SCBF, and a combination thereof. First, the archetypes are designed according to the national building code of Iran, 
which are adopted from ASCE/SEI 7-10, AISC 360-10, and AISC 341-10. The design procedure is then

684 repeated for each archetype by increasing the design base shear coefficient resulting in varying reliability levels for the buildings. To compute the lifecycle cost at each level of base shear coefficient, the initial construction cost of the buildings is assessed, and they are subsequently subjected to a detailed risk analysis using the FEMA P-58 approach. Accordingly, hazard analysis is conducted for Tehran using the scenario sampling method. Thereafter, the nonlinear models of the structures are developed in OpenSees using robust analytical models. The models are then subjected to incremental dynamic analyses to compute the probability distribution of structural responses and collapse fragilities. Detailed assessment of the results yields various insights on the performance of the buildings and their collapse mechanism as byproducts of the present study. Next, the loss analyses determine the expected seismic losses in the lifetime of the buildings. Finally, the expected lifecycle cost of each building is evaluated as the sum of the expected seismic losses and the initial construction cost. The optimal prescribed strength and the corresponding optimal reliability are then evaluated based on the minimum expected lifecycle cost. The main findings of this study are as follows:

- The 50-year optimal reliability index is respectively estimated at 2.0 and 2.1 for midrise IMF and midrise SCBF buildings, and the optimal collapse probability given MCE is $16 \%$ for both systems.

- For the buildings with SCBF system, no increase in the current prescribed strength of the code is advisable, whereas for IMF buildings, there is a lack of sufficient prescribed lateral strength, indicating a need for calibration. As such, it is concluded that the optimal value for the response modification factor for midrise IMFs in Iran is 3.5. With such a calibration, the expected lifecycle cost would decrease by $10 \%$, which could sum up to tremendous amount of nationwide savings.

- Among the loss categories considered in the present study, the direct economic loss due to repair or replacement significantly depends on the economy of the construction industry of the country. Implementing the method proposed herein, it is shown that adopting the repair costs presented in FEMA P-58 manuals to evaluate the seismic risk of buildings located in a developing country, such as Iran, leads to significant errors. This is especially true for components whose repair effort is substantially labor-intensive mainly due to the large discrepancy in labor pay rates.

- The share of seismic losses constitutes up to $45 \%$ of the lifecycle cost. This indicates the prominent need for account for these losses when quantifying the target reliability, especially for highly 
seismically active regions. Moreover, different loss categories may follow different trends, i.e., increasing the earthquake design force may reduce one while increasing another. As such, the target reliability should not be quantified considering any single one of the loss categories, but rather in a holistic manner that accounts for all consequences. Also, due to the significant loss imposed on the society by every death toll or severe injury, the social loss has the highest share in the total loss, and is followed by the direct economic loss.

- A substantial increase in the design base shear leads to merely a small increase in the initial construction cost of the building. For instance, doubling the design base shear of the considered building archetypes here would increase the initial construction cost of midrise IMF and SCBF buildings by a mere $8 \%$ and $3 \%$, respectively. Such results signify that optimizing the prescribed strength level of building codes will have a high benefit-to-cost ratio provided that it does not adversely affect the performance of the building.

The findings of this study although illuminating, may only be valid for the examined building category. Ongoing research by the authors aims to evaluate the optimal target reliability for other structural systems, height levels, seismicity levels, and occupancy types at various importance levels.

Future research must also address the optimal combination of the design base shear and the vertical design force distribution, which is shown here to further reduce the lifecycle cost.

Acknowledgements: The authors thank Sharif University of Technology for Grant No. QA990102. The authors express their gratitude to Dr. Hamed Kashani and Dr. Kiarash M. Dolatshahi from Sharif University of Technology, Mr. Navid Ani, and Mr. Reza Zarrin for insightful discussions. The Authors are also thankful to Messrs. HamidReza Noorbala, Arya Chavoshi, and Mohammad Askari for their assistance with parts of the analyses.

\section{References}

AISC (2010a) Specification for Structural Steel Buildings. ANSI/AISC 360-10, Chicago, Illinois AISC (2010b) Seismic Provisions for Structural Steel Buildings. ANSI/AISC 341-10, Chicago, Illinois

AISC (2010c) Prequalified Connections for Special and Intermediate Steel Moment Frames for Seismic Applications. ANSI/AISC 358-10, Chicago, Illinois

Altoontash A (2004) Simulation and Damage Models for Performance Assessment of Reinforced Concrete BeamColumn Joints. Ph.D. Dissertation, Dept of Civil and Environ Eng, Stanford University, Stanford, CA

Ang AH, De Leon D (1997) Determination of Optimal Target Reliabilities for Design and Upgrading of Structures. Struct Saf 19:91-103. https://doi.org/10.1016/S0167-4730(96)00029-X

Ansal A, Akinci A, Cultrera G, et al (2009) Loss Estimation in Istanbul Based on Deterministic Earthquake Scenarios of the Marmara Sea Region (Turkey). Soil Dyn Earthq Eng 29:699-709. https://doi.org/10.1016/j.soildyn.2008.07.006

ASCE (2017) Minimum Design Loads and Associated Criteria for Buildings and Other Structures. ASCE/SEI 7-16, Reston, Virginia

ASCE (2010) Minimum Design Loads for Buildings and Other Structures. ASCE/SEI 7-10, Reston, Virginia

Askari M, Mahsuli M (2020) Modeling of Epistemic Uncertainties in Seismic Hazard Analysis Based on Reliability Methods. Technical Report, Center for Infrastructure Sustainability and Resilience Research, Sharif University of Technology, Tehran, Iran 
Bezabeh MA, Tesfamariam S, Popovski M, et al (2017) Seismic Base Shear Modification Factors for Timber-Steel Hybrid Structure: Collapse Risk Assessment Approach. J Struct Eng 143:4017136. https://doi.org/10.1061/(ASCE)ST.1943-541X.0001869

BHRC (2014) Iranian Code of Practice for Seismic Resistant Design of Buildings, Standard No. 2800, 4th edn. Road, Housing, and Urban Development Research Center, Tehran, Iran

BHRC (2013a) Design Loads for Buildings, INBC 6, 3rd edn. Building and Housing Research Center, Tehran, Iran

BHRC (2013b) Design and Construction of Steel Structures, INBC 10, 4th edn. Building and Housing Research Center, Tehran, Iran

BLS (2019) United States Department of Labor, Bureau of Labor Statistics. https://www.bls.gov/. Accessed 20 May 2020

Cardone D, Perrone G (2015) Developing Fragility Curves and Loss Functions for Masonry Infill Walls. Earthq Struct 9:257-279. https://doi.org/10.12989/eas.2015.9.1.000

Chopra A. (1995) Dynamics of Structures, 1st edn. Prentice Hall Inc., New Jersey

Cornell CA, Krawinkler H (2000) Progress and Challenges in Seismic Performance Assessment. PEER Center Newsletter, University of California at Berkeley, Berkeley, CA

CPBO (2019) Directive to Executive Agencies, Consultants and Contractors. Country Planning and Budget Organization, Tehran, Iran

Cropper ML, Sahin S (2009) Valuing Mortality and Morbidity in the Context of Disaster Risks. The World Bank Development Research Group, Sustainable Rural and Urban Development Team, Working Paper 4832

CSIRO (2006) Commonwealth Scientific and Industrial Research Organization. https://web.archive.org/web/20060225154902/http://www.cmit.csiro.au/brochures/tech/embodied/. Accessed 11 Nov 2021

CUS (2020) Tehran Municipality ICT Organization, Center for Urban Statistics. https://data.tehran.ir. Accessed 11 May 2021

De Risi MT, Del Gaudio C, Ricci P, Verderame GM (2018) In-Plane Behaviour and Damage Assessment of Masonry Infills with Hollow Clay Bricks in RC Frames. Eng Struct 168:257-275. https://doi.org/10.1016/j.engstruct.2018.04.065

Douglas J, Gkimprixis A (2018) Risk Targeting in Seismic Design Codes: The State of the Art, Outstanding Issues, and Possible Paths Forward. Seism hazard risk Assess 211-223. https://doi.org/10.1007/978-3-319-74724-8_14

EN 1998-1 (2004) Ec8: Design of Structures for Earthquake Resistance, Part 1- General Rules, Seismic Actions and Rules for Buildings. European Committee for Standardization, Brussels

Fayaz J, Zareian F (2019) Reliability Analysis of Steel SMRF and SCBF Structures Considering the Vertical Component of Near-Fault Ground Motions. J Struct Eng 145:04019061. https://doi.org/10.1061/(asce)st.1943-541x.0002330

FEMA-NIBS (2012) Multi-Hazard Loss Estimation Methodology. Hazus-MH 2.1 Technical Manual. Developed by Federal Emergency Management Agency, Conducted for National Institute of Building Science. Washington, D.C.

FEMA (2018a) Seismic Performance Assessment of Buildings, Volume 1- Methodology. FEMA P-58, Prepared by Applied Technology Council, Prepared for Federal Emergency Management Agency. Washington, D.C.

FEMA (2018b) Seismic Performance Assessment of Buildings, Volume 2- Implementation Guide. FEMA P-58, Prepared by Applied Technology Council, Prepared for Federal Emergency Management Agency. Washington, D.C.

FEMA (2020) NEHRP Recommended Seismic Provisions for New Buildings and Other Structures, Volume II: Part 3 Resource Papers. FEMA P-2082, Prepared by Building Seismic Safety Council, Prepared for Federal Emergency Management Agency. Washington, D.C.

FEMA (2009) Quantification of Building Seismic Performance Factors. FEMA P695, Prepared by Applied Technology Council, Prepared for Federal Emergency Management Agency. Washington, D.C.

FEMA (2018c) Assessing Seismic Performance of Buildings with Configuration Irregularities. FEMA P-2012, Prepared by Applied Technology Council, Prepared for Federal Emergency Management Agency. Washington, D.C.

FEMA (2018d) Seismic Performance Assessment of Buildings, Volume 3- Supporting Electronic Materials and Background Documentation. FEMA P-58, Prepared by Applied Technology Council, Prepared for Federal Emergency Management Agency. Washington, D.C.

Ghasemi SH, Nowak AS (2017) Target Reliability for Bridges with Consideration of Ultimate Limit State. Eng Struct 152:226-237. https://doi.org/10.1016/j.engstruct.2017.09.012

Gkimprixis A, Tubaldi E, Douglas J (2020) Evaluating Alternative Approaches for the Seismic Design of Structures. Bull Earthq Eng 18:4331-4361. https://doi.org/10.1007/s10518-020-00858-4

Gudipati VK, Cha EJ (2019) A Framework for Optimization of Target Reliability Index for a Building Class Based on Aggregated Cost. Struct Saf 81:101873. https://doi.org/10.1016/j.strusafe.2019.101873

Heger M, Sarraf M (2018) Air Pollution in Tehran: Health Costs, Sources, and Policies. World Bank, Environmental 
and Natural Resources Global Practice Discussion Paper 06, Washington, D.C.

Hsiao PC, Lehman DE, Roeder CW (2012) Improved Analytical Model for Special Concentrically Braced Frames. J Constr Steel Res 73:80-94. https://doi.org/10.1016/j.jcsr.2012.01.010

Ibarra LF, Medina RA, Krawinkler H (2005) Hysteretic Models That Incorporate Strength and Stiffness Deterioration. Earthq Eng Struct Dyn 34:1489-1511. https://doi.org/10.1002/eqe.495

IRCEO (2019) Iran Construction Engineering Organization. http://www.irceo.net/. Accessed 26 May 2021

Karamanci E (2013) Collapse Assessment and Performance-Based Evaluation Techniques for Concentrically Braced Frames Designed in Seismic Regions. Master of Engineering Thesis, Dept of Civil Eng and Appl Mech, McGill University, Montreal, Canada

Karamanci E, Lignos DG (2014) Computational Approach for Collapse Assessment of Concentrically Braced Frames in Seismic Regions. J Struct Eng 140:A4014019. https://doi.org/10.1061/(ASCE)ST.1943-541X.0001011

Karami Mohammadi R, El Naggar MH, Moghaddam H (2004) Optimum Strength Distribution for Seismic Resistant Shear Buildings. Int J Solids Struct 41:6597-6612. https://doi.org/10.1016/j.ijsolstr.2004.05.012

Karami Mohammadi R, Sharghi AH (2014) Seismic Design of SMRF Structures Using Different Load Patterns and Their Comparison with the Optimum Design. Modares Civ Eng J 14:73-84

Khalili M (2019) Value-Based Seismic Performance Assessment of Common Masonry Façades in Iran. M.Sc. Thesis, Dept of Civil and Environ Eng, Sharif University of Technology, Tehran, Iran

Kim DW, Blaney C, Uang CM (2015) Panel Zone Deformation Capacity as Affected by Weld Fracture at Column Kinking Location. Eng J 52:27-46

Krawinkler H, Zareian F (2007) Prediction of Collapse-How Realistic and Practical Is It, and What Can We Learn From It? Struct Des Tall Spec Build 16:633-653. https://doi.org/10.1002/tal.433

Krawinkler H, Zareian F, Lignos DG, Ibarra LF (2010) Chapter16, Significance of Modeling Deterioration in Structural Components for Predicting the Collapse Potential of Structures Under Earthquake Excitations. In: Fardis MN (ed) Advances in Performance-Based Earthquake Engineering. Springer Netherlands, Dordrecht, pp 173-181

Lignos DG, Hartloper AR, Elkady A, et al (2019) Proposed Updates to the ASCE 41 Nonlinear Modeling Parameters for Wide-Flange Steel Columns in Support of Performance-Based Seismic Engineering. J Struct Eng 145:04019083. https://doi.org/10.1061/(ASCE)ST.1943-541X.0002353

Lignos DG, Hikino T, Matsuoka Y, Nakashima M (2013) Collapse Assessment of Steel Moment Frames Based on EDefense Full-Scale Shake Table Collapse Tests. J Struct Eng 139:120-132. https://doi.org/10.1061/(ASCE)ST.1943-541X.0000608

Lignos DG, Krawinkler H (2011) Deterioration Modeling of Steel Components in Support of Collapse Prediction of Steel Moment Frames Under Earthquake Loading. J Struct Eng 137:1291-1302. https://doi.org/10.1061/(ASCE)ST.1943-541X.0000376

Lignos DG, Krawinkler H (2013) Development and Utilization of Structural Component Databases for PerformanceBased Earthquake Engineering. J Struct Eng 139:1382-1394. https://doi.org/10.1061/(ASCE)ST.1943541X.0000646

Lignos DG, Krawinkler H (2010) A Steel Database for Component Deterioration of Tubular Hollow Square Steel Columns Under Varying Axial Load for Collapse Assessment of Steel Structures Under Earthquakes. In: 7th Int. Conf. on Urban Earthquake Engineering. Center for Urban Earthquake Engineering, Tokyo Institute of Technology, Tokyo, Japan

Lignos DG, Krawinkler H, Whittaker A (2011) Prediction and Validation of Sidesway Collapse of Two Scale Models of a 4-Story Steel Moment Frame. Earthq Eng Struct Dyn 40:807-825. https://doi.org/10.1002/eqe.1061

Mahmoudkalayeh S, Mahsuli M (2021) Ramifications of Blind Adoption of Load and Resistance Factors in Building Codes: Reliability-Based Assessment. Bull Earthq Eng 19:963-986

Mahsuli M, Kashani H, Dolatshahi KM, Hamidia MJ (2018) Kermanshah Province Earthquake. Technical Report, Center for Infrastructure Sustainability and Resilience Research, Sharif University of Technology, Tehran, Iran

Mckenna FT (1999) Object-Oriented Finite Element Programming: Frameworks for Analysis, Algorithms, and Parallel Computing. Ph.D. Dissertation, Graduate Division, University of California at Berkeley, Berkeley, CA

Moghaddam H, Esmailzadeh Hakimi B (1999) On the Optimum Seismic Loading of Multistory Structures. In: 3rd International Conference on Seismology and Earthquake Engineering, Tehran, Iran. pp 669-676

NIST (2017) Guidelines for Nonlinear Structural Analysis for Design of Buildings. Part IIa - Steel Moment Frames. NIST GCR 17-917-46v2, Prepared by Applied Technology Council, Prepared for National Institute of Standards and Technology, Gaithersburg, MD

NIST (2013) Cost Analyses and Benefit Studies for Earthquake-Resistant Construction in Memphis, Tennessee. NIST GCR 14-917-26, Prepared by NEHRP Consultants Joint Venture, Prepared for National Institute of Standards and Technology, Gaithersburg, MD

Rackwitz R (2006) Chapter2, Socio-Economic Risk Acceptability Criteria. In: Haldar A (ed) Recent Developments in Reliability-Based Civil Engineering. World Scientific Publishing Co. Pte. Ltd., Singapore, pp 21-31 
Rahimi H, Mahsuli M (2019) Structural Reliability Approach to Analysis of Probabilistic Seismic Hazard and Its Sensitivities. Bull Earthq Eng 17:1331-1359. https://doi.org/10.1007/s10518-018-0497-3

SCI (2021) Statistical Center of Iran. https://amar.org.ir/english. Accessed 11 May 2021

Stoakes CD, Fahnestock LA (2011) Cyclic Flexural Testing of Concentrically Braced Frame Beam-Column Connections. J Struct Eng 137:739-747. https://doi.org/10.1061/(ASCE)ST.1943-541X.0000326

Tesfamariam S, Skandalos K, Goda K, et al (2021) Quantifying the Ductility-Related Force Modification Factor for 10Story Timber-RC Hybrid Building Using FEMA P695 Procedure and Considering the 2015 NBC Seismic Hazard. J Struct Eng 147:4021052. https://doi.org/10.1061/(ASCE)ST.1943-541X.0003007

Tesfamariam S, Stiemer SF, Dickof C, Bezabeh MA (2014) Seismic Vulnerability Assessment of Hybrid Steel-Timber Structure: Steel Moment-Resisting Frames with CLT Infill. J Earthq Eng 18:929-944. https://doi.org/10.1080/13632469.2014.916240

Uriz P, Mahin SA (2008) Towards Earthquake-Resistant Design of Concentrically Braced Steel-Frame Structures. PEER Report 2008/08, PEER Center, University of California at Berkeley, Berkeley, CA

USGS (2019) United States Geological Survey: Earthquake Lists, Maps, and Statistics. https://earthquake.usgs.gov/earthquakes/browse. Accessed 4 Sep 2019

Vamvatsikos D, Cornell C (2002) Incremental Dynamic Analysis. Earthq Eng Struct Dyn 31:491-514. https://doi.org/10.1002/eqe.141

Wang Z, Yang DY, Frangopol DM, Jin W (2019) Inclusion of Environmental Impacts in Lifecycle Cost Analysis of Bridge Structures. Sustain Resilient Infrastruct 5:252-267. https://doi.org/10.1080/23789689.2018.1542212

Yang TY, Moehle J, Stojadinovic B, Der Kiureghian A (2009) Seismic Performance Evaluation of Facilities: Methodology and Implementation. J Struct Eng 135:1146-1154. https://doi.org/10.1061/(ASCE)07339445(2009)135:10(1146)

Zaman M, Ghayamghamian MR (2019) Risk-Adjusted Design Basis Earthquake: A Case Study of Tehran Megacity. Bull Earthq Eng 17:3777-3799. https://doi.org/10.1007/s10518-019-00625-0

Zareian F, Krawinkler H (2009) Simplified Performance-Based Earthquake Engineering. Report No. 169, The John A. Blume Earthquake Engineering Center, Dept of Civil and Environ Eng, Stanford University, Stanford, CA

Zareian F, Medina RA (2010) A Practical Method for Proper Modeling of Structural Damping in Inelastic Plane Structural Systems. Comput Struct 88:45-53. https://doi.org/10.1016/j.compstruc.2009.08.001

Zibaei Y, Mahsuli M (2021) Seismic Risk Analysis of the City of Golpayegan Using Reliability Methods. Technical Report, Center for Infrastructure Sustainability and Resilience Research, Sharif University of Technology, Tehran, Iran

\section{Statements and Declarations}

\section{Funding}

This work was supported by Sharif University of Technology through Grant No. QA990102.

\section{Competing Interests}

The authors have no relevant financial or non-financial interests to disclose.

\section{Author Contributions}

All authors contributed to the study conception and design. Material preparation and analysis were performed by Kasra Habibi. All authors contributed to the interpretation of the results. The first draft of the manuscript was written by Kasra Habibi with contributions from S. Saeid Hosseini Varzandeh and edited by Mojtaba Mahsuli. All authors read and approved the final manuscript.

\section{Data Availability}

The data generated during the current study are available from the corresponding author on reasonable request. 


\section{Supplementary Files}

This is a list of supplementary files associated with this preprint. Click to download.

- SupplementaryDocumentFinal.pdf 